\title{
AS ESTRATÉGIAS DE CRESCIMENTO DE DOIS GRANDES GRUPOS ECONÔMICOS DO SEGMENTO DE LUXO
}

\author{
Rodrigo Possignolo Rodrigues' \\ Luiz Carlos de Carvalho Júnior²
}

\section{Resumo}

Este artigo tem como objetivo identificar e analisar as estratégias de crescimento das empresas que compõe a chamada indústria do luxo e observar a formação de conglomerados internacionais que operam estratégias alinhadas ao padrão de concorrência setorial dessa indústria. Para tal, foi feita uma revisão bibliográfica e análise de material publicado sobre o setor específico de luxo, além de um levantamento de dados sobre dois conglomerados de luxo internacionais, o LVMH (Möet Hennessy Louis Vuitton) e PPR (Pinaut Primtemps Redoute). Verificou-se que as estratégias que deram sustentação ao crescimento daqueles grupos econômicos foram a diversificação de atividades via fusões e aquisições, aliada à diferenciação de produto baseada em atributos tais como a alta qualidade dos produtos e a distinção da marca.

Palavras-chave: Indústria do Luxo; Diferenciação de Produto; Fusões \& Aquisições

Classificação JEL: L21; M21

\section{INTRODUÇÃO}

Ao longo da história das sociedades, o luxo vem cumprindo o papel de gerador de status, de satisfação pessoal e de transcendência psicológica

Bacharel em Ciências Econômicas pela Universidade Federal de Santa Catarina e Mestre em Marketing da Moda e Comunicação pelo Istituto Europeo di Design. E-mail: rodrigo.possignolo@gmail.com

2 Professor do Departamento de Economia e Relações Internacionais da Universidade Federal de Santa Catarina E-mail: luiz.carvalho@ufsc.br 
da condição humana frente aos demais, o que causa alvoroço, o qual tem processos particulares de formação de preços e de demanda, fugindo ao caráter estritamente racional pressuposto em alguns modelos econômicos que tratam do consumo. O luxo obedece a regras próprias e reflete deformações sociais que foram se consolidando através do tempo e do espaço.

As empresas que fornecem produtos de luxo são normalmente tradicionais, reconhecidas e baseadas em países com forte ligação a esse tipo de consumo e produção. A França e a Itália são os principais países nesse panteão do luxo, seguido pelos Estados Unidos. Cidades como Milão, Paris, Londres, Nova York, Tóquio, são os mercados clássicos, com vias urbanas famosas, shoppings centers, verdadeiros templos do consumo onde um público selecionado circula buscando as novidades dessa indústria. A emergência de certas economias nacionais vem trazendo o luxo para países emergentes, o que dá margem às empresas desse setor buscarem novos mercados para o escoamento de seus produtos, como a China, a Índia, os países do pacifico asiático, além da América do Sul, entre outros.

Crescer ou não crescer, eis a grande questão a qual as empresas de luxo enfrentam, quando se deparam com um ambiente hipercompetitivo, cada vez mais profissionalizado e com apetite em conquistar mercados até então pouco penetrados. Contudo há limites, que se transpostos, põe em risco a legitimidade dos produtos frente ao mercado consumidor. A empresa tem diversas formas de crescer, mas pra isso precisa de vontade e de capacidade de crescimento. Segundo o dicionário Aurélio (FERREIRA, 1999), o luxo consiste em um "modo de vida caracterizado por grandes despesas supérfluas e pelo gosto da ostentação e do prazer; relativo ao fausto, à ostentação e à magnificência". Ou seja, é mais do que mercadorias e serviços, é uma forma de expressar um estilo de vida e de demonstrar status, o que ainda é valorizado, afortunadamente ou não, em nossa sociedade, tanto na oriental, quanto na ocidental, com diferentes abordagens.

O desenvolvimento dos produtos de luxo exige diversos fatores, os quais garantem o sucesso de vendas: exclusividade, utilização de materiais nobres, excelência de qualidade e um valor intangível, ou seja, uma marca, a qual gera credibilidade, reconhecimento e desejo, contribuindo para o sucesso de vendas e perpetuação da empresa no imaginário do consumidor.

Neste âmbito, surge o interesse em estudar o comportamento de certas empresas que vem ganhando espaço nesses mercados, como as que operam 
no setor de luxo, o qual vem mostrando-se eficiente frente às crises, principalmente pela inserção em cada vez mais mercados. Desta forma, busca-se identificar as particularidades dessas empresas e observar em qual posição tal indústria se encontra.

O crescimento da empresa, o processo de diferenciação de produto, a diversificação do portfólio através da aquisição de ativos tangíveis e, primordialmente, intangíveis são os principais pontos de observação desse trabalho. A formação de conglomerados de luxo, como a $\mathrm{LVMH}^{3}$ (França), a PPR ${ }^{4}$ (França), tem se mostrado uma estratégia exitosa, pois deu robustez, em termos de poder de mercado e colocou a indústria do luxo num outro patamar: da empresa familiar, tradicional e centralizada na figura do criador/ empresário, para o controle gerencial, estratégico e multidivisional, gerando visibilidade no mercado e conquista de melhores canais de distribuição, além de ter se configurado um importante receptor de capital de terceiros, os quais buscam rentabilidade e segurança, mostrando certa maturidade do setor, já que exerce um poder de atração para capitais de risco.

O objetivo deste trabalho é identificar e analisar as estratégias de crescimento adotadas na indústria do luxo e observar a emergência de conglomerados nesse setor, a partir do comportamento de dois grandes grupos internacionais: LVMH (Möet Hennessy Louis Vuitton) e PPR (Pinaut Primtemps Redoute).

Para atender a este objetivo, foi feita revisão bibliográfica e a análise de dados disponíveis em artigos divulgados sobre o tema. Para essa incursão, foram utilizadas fontes estrangeiras, as quais possuem um arcabouço mais delineado sobre o assunto, além de materiais divulgados em sites das próprias empresas escolhidas para serem estudadas no presente trabalho, além de consultorias especializadas e fontes jornalísticas, as quais têm reportado os movimentos mais recentes desses conglomerados de luxo.

\section{FUNDAMENTAÇÃO TEÓRICA}

De acordo com as teorias gerenciais, o crescimento aparece com um dos principais objetivos das empresas. Na sua busca pelo crescimento, as

LVMH Moët Hennessy Louis Vuitton S.A.

4 Pinault-Printemps-Redoute S.A. 
empresas se deparam com dificuldades, tais como a conjuntura econômica, a saturação de mercados, a reação dos concorrentes, entre outras. Porém, as empresas não aceitam passivamente tais restrições e buscam superá-las ou amenizá-las, utilizando estratégias de crescimento (GEORGE E JOLL, 1983). A seguir serão apresentadas algumas das principais estratégias de crescimento, dando ênfase às mais importantes para a análise proposta nesse trabalho.

A estratégia de diferenciação de produto consiste na introdução de uma nova mercadoria na linha de produção, a qual seria substituta próxima de alguma outra previamente produzida pela empresa, sendo que será vendida em um dos mercados já supridos pela empresa. Pode se estabelecer através da "modificação na especificação do produto ou na melhoria da qualidade deste" (GUIMARÃES, 1987, P 36-37). Segundo Hitt, Ireland, Hoskinsson (2002, p 161) a diferenciação recai sobre características singulares do produto de uma empresa (exceto custo) que geram valor (real ou percebido) para os clientes.

A diferenciação permite um aumento de preço dos produtos, o que pode melhorar o desempenho da empresa, com o aumento das vendas (já que a diferenciação cria uma maior demanda, na esfera individual, pelo produto), sem contar com a lealdade que vai se constituindo entre os consumidores e o fortalecimento da marca. A conjugação entre valor real e valor percebido vai garantir a defesa dos preços cobrados pela empresa (THOMPSON, STRICKLAND III ; GAMBLE, 2000), assim sendo, as evidências de diferenciação tem de estar claras para que o cliente tenha uma atitude positiva para perceber que um produto é diferenciado.

Desta forma, tem-se a marca como fonte de vantagem competitiva e parte do processo de diferenciação. Segundo Hitt, Ireland e Hoskisson (2002, p 93) "o fato de a marca ser um recurso intangível contribui para a sua sustentabilidade como vantagem competitiva", pois os "recursos intangíveis são menos visíveis, difíceis de serem entendidos e imitados pela concorrência do que os recursos tangíveis".

Um importante fator a ser considerado na estratégia de diferenciação das empresas é o entendimento do comportamento dos consumidores potenciais de seus produtos. Para muitos bens, a sua demanda é influenciada pela difusão de seu consumo, isto é, as pessoas desejam possui-lo porque muitas outras pessoas já o adquiriram, situação observada para os produtos que estão na moda, o que caracteriza a ocorrência de um efeito cumulativo de consumo. As empresas procuram estimular tal comportamento através da 
utilização das atividades de marketing. Por outro lado, existem bens, cuja quantidade demandada será maior, quanto menor for o número de pessoas que o possuem, isto é, depende da sua raridade ou exclusividade. Neste caso, tem-se o efeito de diferenciação de consumo, que se mostra presente na demanda dos bens de luxo. O valor obtido com o bem relaciona-se com o prestígio, status, e exclusividade associados ao reduzido número de outras pessoas que possuem algo similar (PINDYCK; RUBENFELD, 2006, p.112).

A estratégia de diversificação de atividades consiste na modificação da linha de produtos da firma, a partir da inclusão de uma mercadoria a qual será vendida em um mercado que, a princípio, a empresa não participa. Segundo Kon (1994, p 92), as razões básicas para a diversificação são: saturação do mercado, declínio da demanda, pressão da concorrência, obsolescência de produtos, mercados restritos e busca de maior lucratividade. Desta forma, os objetivos da empresa se tornam inatingíveis apenas pela expansão através de produtos e mercados já em operação. Se os fundos retidos forem maiores que o volume exigido para fins de expansão, torna-se possível a realocação do capital de forma rentável, possibilitando o processo de diversificação de portfólio.

No caminho trilhado pela diversificação como ferramenta de administração de risco, o processo de F\&A (Fusões \& Aquisições) se mostra como uma forma mais rápida e mais segura de realizar a estratégia de ampliação de portfólio. A fusão, segundo Hitt, Ireland e Hoskisson (2002, p 276), nada mais é que a integração de operações em bases relativamente iguais entre as empresas fundidas, devido à existência de recursos e capacidades, as quais em conjunto, podem criar uma vantagem competitiva mais robusta à empresa. Já a aquisição, se faz com a compra de uma participação no controle de até $100 \%$ de outra firma, com o intuito de utilizar uma competência essencial mais eficiente, dando à firma adquirente um negócio subsidiário dentro do portfólio da empresa.

Hitt, Ireland e Hoskisson (2002) enumeram como razões para diversificar utilizando as F\&A os seguintes fatores: a demanda por maior poder de mercado, a superação de barreiras de entrada, a redução dos custos e dos riscos no desenvolvimento de um novo produto, a maior velocidade de entrada em um determinado mercado, remodelagem do escopo competitivo da firma, além buscar evitar o acirramento da competição interempresarial. Umas das razões mais fortes é o custo de oportunidade entre começar do zero, em um novo mercado, com maiores despesas e dificuldades que os no- 
vos empreendimentos enfrentarão, frente à possibilidade de entrar de forma imediata, com recursos tangíveis e intangíveis, os quais podem ser a melhor via para a diversificação de atividades, mostrando que a estratégia de F\&A pode ser uma forma menos custosa de se penetrar em determinado mercado.

A estratégia de internacionalização consiste em mais uma forma de expansão, que acontece quando parcela do faturamento da empresa é proveniente de vendas para mercados externos, a qual pode ser adotada através de exportação, licenciamento de tecnologia ou marca, ou a implantação de unidades produtivas em outros países (SOBEET, 2007, p.18).

Mariotto (2007) opina que seria mais simples para uma empresa tentar crescer no seu país de origem, pois nos mercados estrangeiros ela vai se deparar com dificuldades tais como o pouco conhecimento da cultura, costumes, preferências, legislações do país. Em função disto, este autor aponta as razões que levam as empresas a adentrarem nos mercados estrangeiros. A primeira seria a busca por novos mercados, por permitir o crescimento das vendas em proporção superior ao que seria possibilitado pelo mercado doméstico. Ao utilizar os mesmo recursos e competências, a incorporação do mercado externo gera economias de escala e/ou de escopo. Um segundo motivo seria a busca por recursos no mercado internacional, podendo ser um recurso natural ou a mão-de-obra, o que pode estar relacionado à sua disponibilidade ou ao custo de acesso. Recentemente, a implantação de subsidiárias em país estrangeiro tem sido motivada pelo acesso ao capital com menor custo. Outras motivações seriam o acesso a conhecimento especializado, a redução do risco possibilitada pela atuação em mercados com distintas dinâmicas, e o aproveitamento de incentivos fiscais e aduaneiros proporcionados por políticas governamentais de países.

\section{OS CONGLOMERADOS ECONÔMICOS DO SEGMENTO DO LUXO E SUAS ESTRATÉGIAS}

\subsection{A Emergência dos Conglomerados: Formação de Estratégias de Crescimento através de Aquisições}

O luxo, como negócio, desenvolveu-se seguindo diversas direções, entretanto as estratégias de crescimento que obtiveram maior destaque foram 
estabelecidas através do processo de fusões \& aquisições (F\&A), no qual grupos empresariais entraram no segmento de luxo através de aquisições de marcas reconhecidas no mercado, adquirindo os recursos intangíveis e as relações de produção e distribuição que as empresas detentoras dessas marcas já possuíam antes de serem adquiridas, por se entender que o custo de criação de uma nova marca supera o custo de aquisição de uma marca já fixada no imaginário dos consumidores.

Os conglomerados de luxo consistem em empresas com portfólios de marcas renomadas, formados a partir do interesse de grupos empresarias, fundos de investimento ou, até mesmo instituições financeiras, as quais identificaram nas marcas de luxo e no crescimento de seu mercado, um potencial gerador de rentabilidade. Desta forma, uma marca já consolidada no mercado, traria retornos em prazos relativamente menores, reduzindo os custos de entrada, elegendo a prática de aquisições o caminho mais atraente para a diversificação de atividades, buscando novos escoadouros para a acumulação de capital dessas empresas.

As firmas de luxo vêm se estruturando cada vez mais como um oligopólio diferenciado, pois o processo de diferenciação é a estratégia mais utilizada, pois assegura a atratividade dos produtos da firma no mercado, acelerando ou reduzindo o ritmo de diferenciação. Entretanto, essa diferenciação é cultivada em cima de marcas, as quais instituem vínculos com os consumidores, reforçando o valor dos recursos intangíveis como campo de florescimento do desenvolver de novos produtos e de segmentação do mercado, independente da condição financeira da firma que detém uma determinada marca consolidada no imaginário dos consumidores, um valor que suplanta os ciclos de vida dos produtos oferecidos por essas empresas.

Eis o grande gatilho para o processo de formação do oligopólio diferenciado, o qual se aproveita das lealdades às marcas existentes quando busca escoar uma acumulação interna na expansão do portfólio, ou seja, uma diversificação de atividades, auferindo economias de escala e escopo, aumentando o poder de mercado e de barganha e, também montando um escudo financeiro para intempéries cíclicas da economia e dos segmentos específicos de mercado atendidos por esse setor. Um caminho vantajoso é o do processo de F\&A, que além de diversificar os riscos enfrentados nesse setor, fortalece as barreiras de entrada para novos competidores, dando 
novas dinâmicas ao padrão de competição setorial. A posição já adquirida no mercado e as economias no custo de montagem de uma nova estrutura de recursos intangíveis e tangíveis são os principais estímulos para as aquisições, em detrimento do desenvolvimento de novas marcas, as quais demandam tempo para consolidar sua identidade, para focar os segmentos de mercado, para criar relações de produção e distribuição que propulsionem e mantenham o poder de atração frente os consumidores contando com um histórico de sinalização de valor reconhecido pelo público alvo da marca.

Nos anos 1980 aconteceram as primeiras grandes fusões entre empresas de luxo, que causaram uma migração de executivos e investidores para esse modelo de negócio, e nos anos 1990, observou-se a consolidação desse modelo de parceria (via aquisições) entre a gestão administrativa centralizada e profissional com a criação e desenvolvimento de produtos ligados ao luxo. Além da convergência de sinergias já citadas, essas companhias são capazes de reduzir custos, prover acesso a maiores financiamentos para a compra de novas marcas ou para investir em marketing, produção, internacionalização, distribuição, reposicionamento e inovação. Essa prática pode também originar certa aprendizagem gerencial no negócio, abrindo espaço para o deslocamento de executivos e designers entre as marcas do portfólio, fora a capacidade de prover melhores planos de carreira para desenvolver e reter profissionais talentosos, assim como cita Schulz:

\footnotetext{
"Numa indústria impulsionada pela criatividade, uma marca tem de atrair e reter os melhores talentos criativos. Além disso, como a indústria vem se tornando mais dinâmica e competitiva, existe também uma demanda por bons gerentes, desta forma, trava-se uma guerra entre as marcas para a atração desses profissionais." (2002, p 12, tradução do autor $\left.{ }^{5}\right)$.
}

Em termos de competitividade, esses conglomerados acabaram criando padrões de gestão, a partir da coordenação de criadores sob um mesmo teto administrativo, jurídico e financeiro, onde o processo criativo é fomentado para a garantia da diferenciação e da sinalização de valor dos produtos, deixando

\footnotetext{
In this industry driven by creativity, a brand has to attract and retain the best creative talents. In addition, as the industry becomes more dynamic and competitive, there is a need for good managers, thus the war for attracting the best of them.
} 
o controle e o planejamento estratégico para os gerentes profissionais. Tal prática constituiu num chamariz para investimentos, dando uma sustentação financeira jamais experimentada por esse setor, o qual tem a possibilidade de canalizar esse aporte de capital para áreas de inovação de produtos e de processo, para a aquisição de novas marcas ou fortalecimento das já adquiridas; para dinamizar a produção e garantir uma distribuição seletiva, importante para a manutenção da imagem das marcas, além de poder ser utilizado em uma possível internacionalização visando alargar o mercado consumidor. Sem contar que uma cobertura financeira mais sólida auxilia as empresas a lidarem com as incertezas estruturais e sistêmicas, as quais, devido aos ciclos econômicos e particularidades dos mercados, são recorrentes.

Esse avanço na organização empresarial possibilita um maior poder de expansão de mercado, o qual aumenta a amplitude de escoamento dos produtos de luxo. Além dos recursos financeiros e gerenciais para reforçar a presença nos mercados tradicionais, os conglomerados aproveitam o porte conquistado para internacionalizar suas marcas, buscando novos nichos de mercado, que crescem paralelamente com as rendas em ascensão nos países em desenvolvimento. Contudo, essa internacionalização, atualmente, se configura via exportações vindas da matriz, pois existe um movimento de controle da qualidade da produção, o qual tem evitado licenciamentos e outras praticas que possam prejudicar a imagem da marca.

\subsection{O grupo Moët Henessy Louis Vuitton (LVMH)}

O grupo LVMH é o conglomerado de luxo líder mundial, com sede na França, fundado em 1987, a partir de uma operação de fusão entre as empresas Louis Vuitton e Möet Hennessy ${ }^{6}$, sob o comando, desde 1989, de Bernard Arnault. Possui um portfólio composto por mais de 60 marcas de luxo, ilustradas no Quadro 1. É o grupo pioneiro nesse modelo de negócio, sendo um dos maiores complexos empresariais da Europa e principal player da indústria do luxo no cenário mundial.

Em 1984, Bernard Arnault adquiriu uma companhia têxtil falida, a Boussac, a qual, dentre outros ativos, estava inclusa na compra, a marca

Empresa que já passara por um processo de fusão, entre a Möet \& Chandon, fabricante de champagnes, e a Hennessy, fabricante de conhaque de alta qualidade. 
Christian Dior (na época, consistia numa casa de alta costura em decadência, desde a morte de seu homônimo criador em 1957). A estratégia de Arnault começou a tomar forma quando ele se desfez de todos os ativos da Boussac, com exceção da marca Christian Dior. Em 1988, com ajuda da empresa cervejeira britânica Guiness e do banco de investimento francês Lazard Frères, adquiriu $24 \%$ da LVMH, a qual já contava com algumas marcas de bebidas e de moda no portfólio como a Veuve Clicquot e a Givenchy, além da Louis Vuitton, da Henessy e da Möet \& Chandon, as quais compõem o nome do conglomerado. A participação de Arnault no capital da empresa acabou excedendo a dos outros acionistas, e em 1989 se tornou o presidente da holding. Durante os anos 1990, o grupo partiu para uma busca de aquisições e oportunidades de negócios, quando em 2001 o conglomerado realizou uma divisão nos cinco segmentos já citados.

A LVMH é a empresa mais diversificada no setor, já que atua em segmentos que utilizam tecnologias de produção diferentes, contudo que gozam de semelhantes tipos de consumidores. A empresa utiliza o sistema organizacional de divisões por produtos oferecidos geridos de forma independente. Nota-se uma forte internacionalização, pois o grupo possui unidades estratégicas em cinquenta e oito países (LVMH, 2012), o que ilustra um processo de franca expansão internacional, entretanto com uma integração controlada, a qual mantém as filiais internacionais sob o controle da matriz, somente instalando escritórios de distribuição e de marketing. As unidades internacionais são também divididas por segmento de mercado e geridas de forma descentralizada.

A estratégia da LVMH, segundo o próprio site da empresa7, é "buscar representar, em todo o mundo, o que existe de mais refinada qualidade na arte viver ocidental", visando uma associação das marcas do grupo com conceitos como elegância e criatividade, sendo que "o valor cultural que os produtos incorporam harmonizam tradição e inovação, estimulando sonho e fantasia". A criatividade e a inovação são reconhecidamente os fatores de sustentação de longo prazo do sucesso da empresa e a combinação dos dois é tratada como prioridade. A qualidade do produto aspira à perfeição, assim como o reforço da imagem das marcas, essas consideradas "ativos

Disponível em < http://www.lvmh.com/the-group/lvmh-group/group-mission-and-values >. Acessado em 08 de junho de 2012 
insubstituíveis, de valor inestimável”. A reputação atingida pela LVMH é fruto do êxito do processo de diversificação a partir de aquisições de recursos intangíveis, cuja manutenção da imagem e o estímulo à diferenciação de produto em cada uma das marcas se faz a partir do equilíbrio entre a onipresença no mercado e a preservação do ar de exclusividade, o que conta com um aparato poderoso de marketing para promover o valor percebido de cada produto fornecido pela empresa.

QUADRO 1 - Portfólio de marcas do grupo LVMH, divididas por segmento de mercado

\begin{tabular}{|c|c|}
\hline GRUPO MÖET HENESSY LOUIS VUITTON (LVMH) \\
\hline SEGMENTO & MARCAS \\
\hline $\begin{array}{c}\text { VINHOS E DESTI- } \\
\text { LADOS }\end{array}$ & $\begin{array}{c}\text { Moët et Chandon, Dom Pérignon, Veuve Clicquot, Krug, } \\
\text { Mercier, Ruinart, Château d'Yquem, Hennessy, The Glen- } \\
\text { morangie Co, Domaine Chandon California, Belvedere, Bo- } \\
\text { degas Chandon, Domaine Chandon Australia, Cloudy Bay, } \\
\text { Cape Mentelle, Numathia, Newton, Terrazas de los Andes, } \\
\text { Cheval des Andes, 10 Cane Rum, Wenjun. }\end{array}$ \\
\hline $\begin{array}{c}\text { MODA E PRODU- } \\
\text { TOS DE COURO }\end{array}$ & $\begin{array}{c}\text { Louis Vuitton, Céline, Loewe, Berluti, Kenzo, Givenchy, } \\
\text { Dior, Marc Jacobs, Fendi Emilio Pucci, Thomas Pink, Don- } \\
\text { na Karan, Nownees. }\end{array}$ \\
\hline JÓIAS E RELÓGIOS & $\begin{array}{c}\text { TAG Heuer, Zenith, Hublot, Dior Montres, } \\
\text { Chaumet, Bvlgari, De Beers, Fred. }\end{array}$ \\
\hline $\begin{array}{c}\text { PERFUMES E COS- } \\
\text { MÉTICOS }\end{array}$ & $\begin{array}{c}\text { Parfums Christian Dior, Guerlain, Parfums Givenchy, Kenzo } \\
\text { Parfums, BeneFit Cosmetics, Fresh, Make up Forever, } \\
\text { Acqua di Parma, Perfumes Loewe, Emilio Pucci Parfums, } \\
\text { Fendi Perfumes. }\end{array}$ \\
\hline VAREJO SELETIVO & $\begin{array}{c}\text { DFS Galleria, MCS Miami Cruiseline Services, } \\
\text { Sephora, Le Bon Marché Rive Gauché }\end{array}$ \\
\hline
\end{tabular}

Fonte: LVMH (2012)

A LVMH é a líder mundial na produção de champagnes, de vinhos espumantes e não espumantes, os quais são produzidos nas mais famosas regiões vinícolas do mundo. Também conta com o líder mundial dos conhaques, o Hennessy, além da renomada vodka Belvedere. Desta forma, 
o grupo vem desenvolvendo presença no segmento de bebidas de luxo, posicionadas em um nível de maior qualidade do mercado, contando com um eficaz sistema internacional de redes de distribuição. Esse setor vem perdendo participação nas receitas da empresa, já tendo sido cogitada sua venda pra Diageo $^{8}$, demonstrando visível interesse em concentrar os esforços em segmentos que confiram uma rentabilidade sustentável como, por exemplo, o segmento de moda e produtos de couro, nos quais se percebe maior participação no faturamento.

Desde 1980, segundo Lopes (2002) a empresa intensificou os investimentos nos segmentos de perfumes, moda e produtos de couro e em 1996 adquiriu a DFS (Duty Free Stores), uma empresa americana líder mundial em varejo de produtos de luxo para viajantes internacionais, o que veio a se tornar um grande distribuidor dos produtos da LVMH. Essa ligação foi importante para penetrar nos mercados emergentes e criar canais de distribuição comuns para todos os segmentos que a empresa opera, criando uma relação entre os produtos e marcas do portfólio e a exploração de mercados novos.

O segmento de vinhos e destilados comporta um extrato de produtos que possibilitam um maior acesso dos consumidores, posto que a segmentação de mercado possibilita o atendimento de diversas classes de consumidores de luxo, e um portfólio distinto e diversificado tem a capacidade de abastecer os canais de distribuição selecionados, de forma mais autônoma (pois possui uma gama mais completa de produtos, os quais podem ser vendidos conjuntamente), que contribuem para amparo e a propulsão da percepção dos produtos como itens de luxo.

Apesar de não ser comum em outros conglomerados, esse segmento é importante por ser um dos fundadores da LVMH, visto que compõe o próprio nome do grupo, sem contar que pode ser considerado como uma ponte para os outros segmentos, podendo assegurar a penetração em novos mercados e agregar valor percebido para o grupo como um todo, devido à conexão das bebidas finas, principalmente do champagne, com a essência do que é considerado luxo.

Disponível em <http://www.istoedinheiro.com.br/noticias/I3I4_O+LVMH+VENDERA+A+ALMA+A+DIAGEO, acessado em 27/05/2012 
- Moda \& Produtos de Couro (Fashion \& Leather Goods)

Mantém-se como segmento de maior participação na rentabilidade do conglomerado e também a principal plataforma de publicidade e de diferenciação de produto. Esse segmento foi fonte de diversas batalhas com outras empresas por aquisição de marcas, as mais recentes foram a disputa pela Gucci, adquirida pelo grupo PPR e pela Hermés, que ficou com os herdeiros do fundador, por enquanto. O segmento de Moda \& Produtos de Couro é importante devido às diferentes naturezas das marcas que possui, capitaneadas pela Louis Vuitton, onde há uma estimativa de que a marca corresponde a $37 \%$ das vendas do conglomerado (ECONOMIST, 2012), sendo líder mundial em produtos de couro de ponta, que a partir da direção criativa de Marc Jacobs, um designer de moda americano que revitalizou a diferenciação de produto da marca, tornando-a uma das mais valiosas do mundo.

A estratégia da Louis Vuitton resume-se na utilização dos melhores couros, transformados em produtos que conjugam tradição na perfeição artesanal, qualidade estética e aspectos de vanguarda, comercializados habilmente para não diluir o poder da marca. Bolsas como a Speedy, a Neverfull, a Grafitti (um dos maiores sucessos de vendas da gestão Marc Jacobs), e a recém-lançada Alma, fazem consumidoras do mundo todo formarem filas de espera (as edições são limitadas para garantir o aspecto de raridade do produto de luxo) para despenderem valores na casa dos milhares para a aquisição desses itens de consumo.

Essas marcas são uma plataforma de segmentação de mercado, possibilitando a realização da estratégia de diferenciação de produto mais dinâmica, devido ao curto ciclo de vida dos produtos que lançam. Há um esforço em identificar o perfil dos consumidores e operar o desenvolvimento de itens que atendam esses nichos de consumo, alongando as marcas ou utilizando cada uma delas para atender segmentos de naturezas diferentes. A Dior quando adquirida pelo grupo possuía mais de 350 contratos de licenciamento e produtos, o que ampliou o número de consumidores atingidos, mas tal estratégia acabou afetando negativamente a imagem da marca ${ }^{9}$, pela

Caso recorrente em marcas de luxo, quando o licenciamento passa dos limites, simbolizado pelos excessos de uma marca, tem-se o exemplo da Pierre Cardin. Devido a infinidade de produtos sob a insígnia da marca, a Pierre 
dificuldade de exercer o controle de qualidade e o respeito ao horizonte de diversificação que a marca permitia.

A estratégia da LVMH foi recomprar todos esses licenciamentos, esperar um tempo até que os produtos desse período esgotassem nas prateleiras, e reposicionar a marca, a partir da retomada da produção controlada pela própria empresa e a contratação de um designer de moda recém-formado, John Galliano, que rejuvenesceu a aura da marca e devolveu o caráter luxuoso que sempre acompanhou a Dior. A prova da eficácia dessa estratégia é que mesmo com a saída desse criador, devido a problemas pessoais, a marca continua, com um novo criador, Raf Simmons, que propõe uma nova posição no mercado, entretanto sem prejudicar a imagem da marca e a sinalização do valor que ela ostenta.

O conglomerado é conhecido por respeitar a criatividade de seus designers e apostar em novos talentos, como Marc Jacobs na Louis Vuitton, John Galliano na Givenchy e posteriormente na Dior e em Alexander McQueen na Givenchy. Esse pode ser considerado um dos fatores de sucesso e de extensão do poder de mercado. Essa convivência gerencial e criativa conseguiu conferir um alcance global mais amplo, com uma sinalização de valor que alterou de forma positiva a percepção dessas marcas, acarretando uma demanda em constante expansão e um reconhecimento social mais vasto. Enxerga-se que um dos fatores de sucesso no setor é esse respeito à criatividade e à inovação além da aposta em criadores talentosos, que através da imagem de moda, incitam o consumo de produtos de couro, como bolsas e sapatos, além de perfumes, cosméticos e uma infinidade de produtos que aproveitem a imagem da marca, sem esgotar seu poder de fascinação.

Os desfiles de moda, nas semanas de Paris, Nova York, Milão, as propagandas, as relações publicas, o patrocínio a eventos, a contratação de embaixadores e embaixadoras, como modelos, atores de Hollywood, personalidades reconhecidas nos mercados que o conglomerado busca conquistar, são os dinamizadores dessa estratégia de crescimento de diferenciação de produto. O marketing de moda e acessórios garante a fixação das marcas no imaginário coletivo e permitem uma extensão destas buscando atender segmentos mais amplos do mercado.

Cardin viu seu poder de conquista minguar frente a imensidão de itens das mais diversas naturezas que mancharam a imagem luxuosa da marca, não tendo mais o apelo de tempos passados. 
O segmento de Moda \& Produtos de Couro se mostra como a grande plataforma de comunicação dos conglomerados, considerado um pivô estratégico para sinalizar valor em menores intervalos de tempo, devido à sazonalidade que lhe é peculiar.

- $\quad$ Perfumes \& Cosméticos (Parfums \& Cosmetics)

O grupo é um dos principais atores no setor de perfumes, maquiagens e produtos de beleza, sendo esse setor baseado essencialmente num portfólio de marcas com presença internacional. Além das já reconhecidas, o grupo desenvolve marcas de grande potencial de crescimento, mas sem tanta presença internacional. Esse segmento está intimamente ligado ao segmento de Moda \& Produtos de Couro, pois é a principal via de extensão das marcas do segmento citado, aproveitando-se dos ganhos de imagem e de marketing, onde produtos mais perenes e acessíveis, os quais resistam à sazonalidade natural ao mercado de moda, são lançados, podendo atender uma demanda maior que o segmento do qual é derivado. Esses dois segmentos somados, nos últimos dez anos, tem gerado metade do faturamento da empresa.

Interessante observar que esse segmento tem uma comunicação maior com o grande público. Perfumes da Dior como o J'adore, o Addict, o Poison, e diversos outros, contam com propagandas de maior alcance, pois esse segmento permite um nível de consumo mais amplo. Os perfumes e os cosméticos são portas de entrada aos consumidores pertencente a uma classe de menor poder aquisitivo, mas com apetite pelo adicional de valor que um item de marca pode trazer. O design das embalagens, a vibração e a força da publicidade, a seleção de matéria prima de ponta, garantem essa extensão do poder das marcas de moda, e também cria uma demanda mais forte para esses produtos de menor preço individual, permitindo uma penetração massiva do conglomerado em maiores fatias dos mercados consumidores.

Contudo, é um segmento que vem perdendo participação no faturamento da empresa, pois foi constatada uma perda de cinco pontos percentuais no seu faturamento global no período de 2001 (18,24\%) a $2011(13,50 \%)$, frente a um crescimento do seu setor complementar Moda \& Produtos de Couro que passou de $29,54 \%$ para $36,82 \%$ no mesmo período. 
- Joias e Relógios (Watches \& Jewellery)

Esse é o segmento mais recente do grupo, o qual atende uma classe de consumidores superior comparados aos segmentos já citados, o qual possui um portfólio de marcas de luxo com posições de mercado altamente complementares. O grupo se beneficia da estatura da TAG Heuer, sendo esta uma líder mundial em relógios com alta precisão em termos de marcação do tempo e da solidez da marca Hublot, além de possuir outras marcas estratégicas no setor. Este segmento é o que possui menor participação no faturamento do conglomerado, mas é o que possui maior taxa de crescimento percentual.

A importância desse segmento é cabal numa estratégia de longo prazo, pois garante um nível de rentabilidade maior e mais sólido, devido ao ciclo de vida maior de produtos como colares, brincos, pulseiras manufaturados com gemas preciosas, alem de relógios e outras extensões cabíveis, como óculos e canetas. O preço unitário é relativamente maior e o aspecto de raridade, exclusividade e difícil acesso formam um espectro interessante na comunicação do valor percebido para clientes de maior poder aquisitivo. Esse segmento tem sido prioridade para o presidente do conglomerado Bernard Arnault (ECONOMIST, 2012), pois pode representar uma base de equilíbrio financeiro de maior duração em longo prazo.

\section{- Varejo Seletivo (Selective Retailing)}

Nesse setor, o conglomerado opera na Europa, na America do Norte, na Ásia e no Oriente Médio. Os negócios são conduzidos em dois segmentos: varejo projetado para consumidores que são viajantes internacionais, onde atuam empresas como DFS (Duty Free Service) e Miami Cruiseline, líderes em seus mercados; e em varejos seletivos, representados pelo Le Bon Marché, uma loja de departamentos tradicional com uma atmosfera diferenciada localizada em Paris e pela Sephora, que é considerada a mais inovadora no segmento de varejo ligado à beleza, na qual o conglomerado teve papel crucial no reposicionamento desta marca. A principio, as lojas da Sephora, no momento da aquisição, eram demasiadamente grandes, o que causava uma impressão errada aos consumidores de luxo, o que refletia no mau desempenho no faturamento. Posteriormente, a gestão da LVMH 
operou uma diminuição do tamanho das lojas e uma adição de serviços, como salões de beleza, sem contar a oferta de um amplo leque de produtos das marcas do conglomerado, desenvolvendo um ponto de distribuição seletivo integrado aos interesses do grupo, garantindo uma inflexão nos resultados decadentes.

Esse segmento é muito sensível a choques internacionais, principalmente os que ocorrem na Ásia, pois é onde está mais bem posicionado. A margem de lucro é uma das menores do conglomerado, entretanto configura-se como importante escoadouro de produtos de todos os segmentos da LVMH. O varejo seletivo é uma forma interessante para a estratégia de internacionalização, devido ao controle inicial do grupo e a utilização do espaço para distribuir de forma adequada os produtos, já criando vínculos com os mercados a serem conquistados. Contudo, mantém sua participação estável no faturamento da empresa, correspondendo, em média, a um quarto do total da receita da LVMH.

\section{$* * *$}

O grupo LVMH é o baluarte no setor de luxo, portanto um ditador de formas de concorrência de mercado, já que sua ampla diversificação somada a uma cobertura internacional eficiente e descentralizada, garante a disponibilidade adequada no mercado de luxo (distribuição seletiva) possibilitando a cobertura eficiente da demanda por seus produtos. Os cinco segmentos asseguram ao grupo uma maior solidez, ou seja, quando algum deles está demonstrando um baixo desempenho, pode-se utilizar recursos acumulados nos segmentos que obtiveram sucesso para balancear a situação do grupo, principalmente em momentos de incerteza na economia e nos mercados atendidos pelo grupo. O aproveitamento das sinergias existentes, devido ao caráter luxuoso de todos os produtos da marca, garante uma série de economias de marketing e de distribuição o que vai desenvolvendo curvas de aprendizado na gestão do luxo.

\subsection{O grupo Pinaut Primtemps Redoute (PPR)}

O PPR é um grupo francês formado em 1963, que montou sua divisão de luxo entre 1999 e 2004, período no qual o grupo foi comprando par- 
ticipações no Grupo Gucci até ser sócio majoritário (em 2004 já possuía 99,4\% de participação). O grupo abrange mais de 15 marcas (Quadro 2) inseridas nas seguintes divisões: de Luxo (que conta com o subsegmento de Moda \& Produtos de Couro e o de Joias \& Relógios), de Esportes \& Estilo de Vida e de Varejo.

QUADRO 2. Portfólio de marcas do grupo PPR, divididas por segmento de mercado

\begin{tabular}{|c|c|c|}
\hline \multicolumn{2}{|c|}{ GRUPO PINAUT PRIMTEMPS REDOUTE (PPR) } \\
\hline SEGMENTO & MARCAS \\
\hline \multirow{2}{*}{ LUXO } & $\begin{array}{c}\text { MODA E PRODUTOS } \\
\text { DE COURO }\end{array}$ & $\begin{array}{c}\text { Gucci, Bottega Veneta, Yves Saint Laurent, } \\
\text { Alexander McQueen, Balenciaga, Brioni, Sergio } \\
\text { Rossi, Stella McCartney }\end{array}$ \\
\cline { 2 - 4 } & JÓIAS E RELÓGIOS & \begin{tabular}{c} 
Boucheron, Girard-Perregaux, JeanRichard \\
\hline ESPORTES E ESTILO DE VIDA
\end{tabular} \\
\hline \multicolumn{2}{|c|}{ VAREJO } & Puma, Volcom, Electric \\
\hline
\end{tabular}

Fonte: Site da PPR (2012) (www.ppr.com/en/brands)

O grupo PPR é comandado por François Pinaut e atua com três segmentos comuns com sua maior concorrente do setor, a LVMH. O grupo possui marcas importantes no cenário internacional da moda e vem tentando entrar no setor de jóias e relógios, todavia o seu portfólio de empresas de varejo vem sendo desfeito, configurando uma estratégia de concentração de esforços nos outros segmentos, os quais apresentam um maior potencial de crescimento. Diferente do segmento de Varejo Seletivo da LVMH, as empresas da PPR não são canais de distribuição direto dos produtos da marca, o que mostra uma falta de sinergias que justifica essa reestruturação. A novidade é a diversificação na direção de setores ligados a esportes e estilo de vida, inaugurado com a aquisição da marca Puma, marca esportiva global e, posteriormente, da Volcom, marca ligada a esportes radicais, o que pode ser identificado como uma guinada no modelo de negócio. 
TABELA 1 - Participação dos segmentos no faturamento do grupo LVMH (\%) entre 2001 e 2011

\begin{tabular}{|c|c|c|c|c|}
\hline Ano & Luxo & Varejo Seletivo + FNAC & $\begin{array}{c}\text { Esportes \& } \\
\text { Estilo de Vida }\end{array}$ & $\begin{array}{c}\text { Total } \\
\text { (em mi de } €)\end{array}$ \\
\hline 2005 & $17,89 \%$ & $82,05 \%$ & $0,00 \%$ & $16.937,90$ \\
\hline 2006 & $20,94 \%$ & $79,01 \%$ & $0,00 \%$ & $17.025,60$ \\
\hline 2007 & $19,57 \%$ & $71,80 \%$ & $8,63 \%$ & $19.760,90$ \\
\hline 2008 & $16,73 \%$ & $70,88 \%$ & $12,50 \%$ & $20.201,20$ \\
\hline 2009 & $20,52 \%$ & $64,69 \%$ & $14,89 \%$ & $16.524,60$ \\
\hline 2010 & $36,44 \%$ & $39,09 \%$ & $24,59 \%$ & $11.007,80$ \\
\hline 2011 & $40,21 \%$ & $34,06 \%$ & $25,81 \%$ & $12.227,20$ \\
\hline
\end{tabular}

Fonte: PPR ANNUAL REPPORT (2005-2011) - compilado pelo autor

A empresa tem buscado sua transformação estratégica em um grupo especializado em vestuário e acessórios (desfazendo-se do segmento de varejo que o originou), organizados em torno dos segmentos de Esportes e Estilo de Vida, tendo a Puma como referência, o qual já participa de um quarto do faturamento do grupo (TABELA 1), e de Luxo, participação que vem aumentando significativamente no faturamento da empresa, que de 2005 a 2011, incrementou vinte e três pontos percentuais no rendimento global do grupo, capitaneado pela Gucci - as vendas da marca homônima representam $64 \%$ do lucro dessa divisão do conglomerado. O setor de varejo, antes o negócio predominante, com $82,05 \%$ de faturamento em 2005, já respondia em 2011 por uma participação relativamente menor, de 34,06\%, indicando o processo de downscoping na reestruturação da estratégia de crescimento da empresa.

O conglomerado opera as marcas respeitando os padrões de concorrência do mercado, ou seja, permitindo que elas desfrutem de certa autonomia, aspecto central para garantir a identidade e a expressão criativa, fatores cabais para a diferenciação de produto, o qual garante o sucesso nessa indústria. A PPR vem tomando um caminho que se identifica como um conglomerado onde há a divisão de luxo, diferente da concorrente LVMH (que trabalha puramente com marcas e produtos de luxo e varejo especializado para tais), e uma divisão de outra natureza, a qual pode garantir rentabilidade em períodos que o mercado de luxo esteja desaquecido. 
A PPR já conta com marcas com forte potencial diferenciador, que já estendem sua atuação no mercado, com perfumes como Flora, Guilty e Gucci by Gucci, da marca de moda Gucci, também a marca de moda Yves Saint Laurent com, por exemplo, a fragrância Parisiennne, que contou com propagandas estreladas pela modelo Kate Moss, exemplificando a contratação de figuras de mídia que completam a estratégia de diferenciação.

A análise da PPR acaba repetindo o que já foi colocado sobre a LVMH, entretanto é oportuno colocar que mesmo com o grande poder da segunda, existiu espaço para a emergência da primeira, mostrando que o caráter gradual do luxo, permite uma segmentação de mercado tão grande que possibilita um nível de concorrência entre conglomerados, além das marcas que operam de forma autônoma. A luta por marcas, por mercados, por fornecedores e por canais de comunicação e distribuição, dinamizam a formação das estratégias de crescimento e impelem maiores esforço para desenvolver produtos melhores e para adquirir novos campos de diferenciação e diversificação de atividades, ou seja, marcas ainda operando de forma autônoma, definindo padrões de concorrência particulares.

\section{CONSIDERAÇÕES FINAIS}

Com a adoção de estratégias, a empresa busca uma posição sustentável frente às incertezas e particularidades apresentadas pelo mercado, garantindo uma condução da acumulação de capital - que as empresas têm acesso - para uma postura de sustentação de crescimento em longo prazo. As estratégias de crescimento das empresas que operam no mercado considerado de luxo devem ser traçadas respeitando os padrões de concorrência desse setor industrial e as peculiaridades que compõem toda a fascinação que os produtos dessa natureza são capazes de originar.

No mercado de luxo um conglomerado que busque sucesso deve estar sintonizado com o balanço entre valor real e valor percebido, e com a constante sinalização desses valores, respeitando a autonomia de seus criadores e desenvolvedores de produtos, entendendo os limites que um produto de luxo precisa para conservar o prestígio de seus recursos intangíveis. Isso consiste em uma plataforma considerável quando se pensa nas estratégias de crescimento como diferenciação de produto, 
diversificação de atividades, integração vertical e internacionalização no âmbito da indústria do luxo.

Os grupos LVMH e PPR foram bem sucedidos no trato com o incremento de competição e adequação ao dinamismo dos padrões de concorrência nos setores em que atuam. A capacidade de gestão estratégica e criativa que os conglomerados atingem é essencial para cumprir o rol de protocolos que a indústria do luxo impõe para quem deseja fazer parte desta, sendo essencial para impulsionar o processo de diferenciação de produto e de diversificação de atividades. Através das F\&A, empresas ligadas ao luxo, à moda, ao setor de joias e relógios, e de qualquer setor que lide com esse mercado cercado do caráter suntuoso, das pompas e das circunstâncias, pode adquirir competitividade com a obtenção de diversas economias de escala e escopo e neutralização de custos de entrada.

\title{
GROWTH STRATEGIES OF TWO LARGE COMPANIES IN THE LUXURY GOODS SECTOR
}

\begin{abstract}
This article aims to identify and analyze the growth strategies of companies that make up the so-called luxury industry and observe the formation of international conglomerates operating strategies aligned to the standard of competition in this industry. For this we made a literature review and analysis of published material on the specific industry of luxury, and a survey of data on two international luxury conglomerates, LVMH and PPR. It was found that the strategies that have supported the growth of those companies were diversifying activities through mergers and acquisitions, coupled with product differentiation based on attributes such as high product quality and brand distinction.
\end{abstract}

Keywords: Luxury Goods Industry; Product Differentiation; Mergers \& Acquisitions

JEL Classification: L21; M21 


\section{REFERÊNCIAS}

ECONOMIST, The Empire of Desire, jun de 2012. Disponível em $<$ http:// www.economist.com/node/21556270> Acessado 14 de maio de 2012

FERREIRA, A. B. H. Aurélio século XXI: o dicionário da Língua Portuguesa. 3. ed. rev. e ampl. Rio de Janeiro: Nova Fronteira, 1999.

GEORGE, Kenneth D.; JOLL, Caroline. Organização industrial: concorrência, crescimento e mudança estrutural. Rio de Janeiro: Zahar, 1983. 393p.

GUIMARÃES, Eduardo Augusto. Acumulação e crescimento da firma: um estudo de organização industrial. Rio de Janeiro: Guanabara, 1987. 196p.

HITT, Michael A.; IRELAND, R. Duane; HOSKISSON, Robert E. Administração estratégica. São Paulo: Pioneira Thomson Learning, 2002. 549 p. ISBN 8522102708 (broch.)

KON, Anita. Economia industrial. São Paulo: Nobel, 1994. 212 p.

KONIGS, A. \& SCHIERECK, D. Wealth creation by M\&A activities in the luxury goods industry, in: Working Paper № 7-2006 January 2006 $<$ http://www.ebs.de/fileadmin/redakteur/funkt.dept.finance/schiereck/WorkingPapers/Volltext/WP2006-07.pdf>. Acessado em: 08 de março de 2012

LOPES, T.S. (2002). Brands and the evolution of multinationals in alcoholic beverages, Business History, 44/3, 1-30.

LVMH (Möet \& Hennessy Louis Vuitton group); Annual Report 2002-2011 Disponível em:

$<$ http://www.lvmh.com/investor-relations/documentation/reports $>$. Acessado em: 19 de abril de 2012.

MARIOTTO, Fábio L. Estratégia internacional da empresa. São Paulo: Thomson Learning, 2007. 
PYNDICK, Robert S.; RUBINFELD, Daniel L. Microeconomia. São Paulo: Pearson Prentice Hall, 2006.

PPR Annual Report 2005-2011. Disponível em < http:/www.ppr.com/ en/2011-annual-report $>$ Acessado em 17 de abril de 2012

SCHULZ, Rodrigo Sepúlveda. Can Luxury Goods Conglomerates Sustain Above-Normal Returns? The Gucci Group Case, in: 'Industry and Competitive Analysis' course, Professor Karel Cool, INSEAD MBA Program, Abril 2002. Disponível em <http://sepulvedanet.free.fr/gucci.pdf $>$ Acessado em 12 de abril de 2012

SOBEET - Sociedade Brasileira de Estudos de Empresas Transnacionais e da Globalização Econômica. Internacionalização das empresas brasileiras. São Paulo: Clio Editora, 2007.

THOMPSON, Arthur A.; STRICKLAND III, A. J.; GAMBLE, John E. Administração estratégica. 15. ed São Paulo: McGraw Hill, 2008. 